\title{
TERROR Y FANTASÍA EN LA NOVELA EL ANTRO DE LAS BRUJAS DE ALFONSO LAZARTE
}

\author{
Alberto Chavarría Muñoz \\ Escritor y docente UNCP \\ Investigador en Cultura y Gestión cultural \\ aldach9@hotmail.com
}

RESUMEN: Relacionar historia y psiquis a partir de un acto ideológico como es la literatura resulta clave para comprender un proceso de desarrollo social, más aún comprenderla a partir de las sublimaciones indicadoras de actitudes y comportamientos de los miembros de la sociedad huancaína, en el Perú de los años 50 del siglo XX. Las sublimaciones, que expresan el terror y la fantasía en la novela El antro de las brujas, demuestran dos situaciones: un discurso de auto exoneración en el fallido desarrollo de la ciudad y, al mismo tiempo, un cuestionamiento muy severo sobre la psicología del habitante de la ciudad, del sector hegemónico como del subalterno.

PALABRAS CLAVE: Ciudad patricia, burguesía señorial, fantástico, sublimación, neurosis.

\begin{abstract}
Connecting history and psyche through an ideological act like literature is essential to understand a process of social development, especially to understand it from the point of view of phenomena of sublimation that reflect different attitudes and behavior of the society in Huancayo, Peru in the 1950s. Sublimation expressing horror and fantasy in $E l$ antro de las brujas reflects two situations: a self-exoneration discourse in the failed development of the city and at the same time, a serious questioning of the psychology of city residents, of the hegemonic sectors of the subaltern.
\end{abstract}

KEYWORDS: patrician town, stately bourgeoisie, fantastic, sublimation, neurosis

Empecemos con un punto de partida válido: "Recordemos los datos del problema: en el universo evocado por el texto, se produce un acontecimiento - una acción - que proviene de lo sobrenatural (o de un falso sobrenatural); por su parte, éste provoca una reacción en el lector implícito (y generalmente en el héroe de la historia), que denominamos "vacilación", y "fantásticos" los textos que la hacen vivir" (Todorov 1971: 58).

La novela "El antro de las brujas", que cualifica como fantástica, es la historia de un hombre, Juan, que, luego de varios años de ausencia regresa a su hogar en Huancayo, encuentra que su mujer se ha ido con otro hombre. Este hecho, aparentemente un caso de infidelidad, desbroza un proceso de "reviviscencia arcaica", es decir, permite la salida monstruosa y sangrienta del ser innato, un felino, que llevaba como parte de su proceso evolutivo.

La lucha entre lo natural hoy, la evolución del ser como consciencia cultural y biológica, y lo sobrenatural hoy también, la existencia primordial de seres violentos, asesinos y 
sanguinarios que son controlados por ese consciente, genera la tensión novelística fantástica, tanto en el lector como en el protagonista y en algunos figurantes en la novela.

Sin embargo, esa tensión fantástica no hubiera tenido un derrotero productivo literario sino se creaba mayor incertidumbre con la supuesta muerte de Juan y no se hubieran sabido las razones de la metamorfosis. Por ello, Lazarte introduce un largo discurso "científico", del profesor Veritas, sobre el evolucionismo, las determinaciones y los alcances de "las semejanzas remotas del hombre". Precisa que todas las formas de evolución y construcción físico-genéticas, con sus correspondientes ánimas o formas de consciencia, son una sumatoria que está presente y nada olvidado ni destruido. Que es la cultura, en la acepción freudiana, la gran represora, el que impide su aparición constante. Si habrá una metamorfosis será, dice Veritas, en circunstancias excepcionales donde la cultura es rota y el ello ya no basta para detenerlo.

Coincide el profesor, por la generalidad, con Freud (1974) : "Es posible, desde luego, que también en lo psíquico mucho de lo antiguo - como norma o por excepción - sea eliminado o consumido a punto tal que ningún proceso sea ya capaz de restablecerlo y reanimarlo, o que la conservación, en general, dependa de ciertas condiciones favorables" (Pág. 72).

Al final de la novela El antro de la brujas, la razón (encarnada en el comisario de la policía) concluye que se trata de un caso "de alucinación o enfermedad colectiva". Lo increíble está dado por la no captura del Monstruo en tanto se lo llevaron las brujas hacia destinos ignotos. Sin embargo, la carta epilogal termina con las dudas. Luego de hacer un resumen de su vida, Juan, resalta que no es consciente del proceso de transformación o metamorfosis. Solo sabe las consecuencias. Se siente apresado entre los poderes evolutivos y los constructos sociales, que es solamente un objeto de fuerzas extrañas: la biología y la cultura. El caso es que la carta epilogal deja un hecho: no hay criminal a quien sancionar.

Esta misma carta, al desarrollar un final abierto, nos muestra otra faceta de lo fantástico: la mantención de la indecisión. La pregunta que se impone es: ¿si no fue capturado (o lo que es lo mismo, si no fue muerto o enterrado) el monstruo, éste volverá? Con ella aceptamos lo que Louis Vax acentúa: "El arte fantástico ideal sabe mantenerse en la indecisión" (Citado por Todorov: 26 ).

\section{Significaciones: Terror y fantasía en "El antro de la brujas"}

La primera articulación de terror la creará el narrador, omnisciente y en tercera persona, utilizando ciertos conceptos o frases que se mueven en el ámbito coloquial y que son entradas hacia situaciones de incertidumbre de por sí aceptadas, que, sin embargo, crean zozobra y adquieren cariz de cierta morbosidad. Como los niños cuando ven una película de terror por Tv y que les genera miedo, incluso pesadillas, pero que no quieren despegarse del aparato hasta ver la totalidad. Es decir, "quieren gozar" el miedo.

La atmósfera novelística, que es lo que se crea con esas frases o conceptos, se explicita en los títulos: En la amazonía misteriosa (la selva aparece misteriosa por lo ignoto y diferente al que no vive ahí, además, insertar la mitología del Yacumama lo acentúa), La leyenda del "Ay, ay Mama" (toda leyenda suena a tiempos inmemoriales, a primitivismo o ruptura de realidad. Además, el uso de las comillas es indicador de ¡Atención, cuidado, no lo pases por 
alto, es importante!, lo cual es significativo en la comprensión textual), El Gran Parú (podría haber utilizado su nombre más común: Ucayali, pero para generar un efecto exótico y muy vinculado a lo extraño y totalmente diferente lo usa en idioma nativo y con un adverbio de cantidad (reforzador de mayor misterio) como una locución específica al objetivo), Hacia la tierra natal (que podría recordar el regreso a Ithaca de Ulises pero sin odisea, como si saliera de lo oscuro y misterioso y volviera al lugar "donde se figuraba (cursiva nuestra: p. 23) que una amantísima esposa le esperaba desde hacía tiempo con los brazos abiertos" (misma situación de Penélope); sin embargo, algo le avisaba que no sería así: "Sintió en esos instantes que algo pugnaba por deshacerse de él y dejó escapar un tosco ronquido" (p. 30), lo que indicaba un extraño presagio), Fatídico augurio (un graznido de búho, truenos y un fuerte vendaval, "que abrió la ventana de par en par" y la aparición "de una figura horrorosa", muestran la asociación: noche, malaseña, tormenta y acontecimiento sobrenatural), El antro de las brujas (no usó aquelarre porque es una idea europea y destruiría el misterio, sino la idea nuestra de cueva o covacha para incrementarla; la brujería está siempre presente entre nosotros, explicita además, la educación occidental de los niños y niñas), Extraña visión en la ciudad (el colapso psicológico de la muchedumbre como factor sobrenatural), En el teatro del crimen (inicio de la zozobra y de la morbosidad popular, asociada a los medios de comunicación), ¿Es una fiera o un ser humano el criminal? (es la forma folletinesca de acentuar el suspenso y el melodrama), Otra fechoría del Monstruo (el uso de una palabra culta acentúa la cualidad del ser que es monstruoso, o sea perversa y cruel), El peligro de parecerse a otro (se insiste en el melodrama para pasar al drama, el riesgo no está en la diferencia sino en lo común, la idea básica lleva a la singularidad como seguridad beneficiosa y a la homogeneidad como riesgo y amenaza), En el cementerio (cualquier lugar de muerte causa repugnancia y miedo, en lugar de descanso la idea deslizada es la de culpa y presencia anímica, la idea del no vacío sino de lo etéreo y que al ser perturbada puede causar conmoción), Audaz opinión sobre la naturaleza Bio-Psíquica del criminal (dentro del contexto de la novela genera mayor incertidumbre, pues rompe con los esquemas sobre la criminalidad, por ello el adjetivo para insistir en la naturaleza desconocida del ser humano y sumir al lector en la desolación sobre sus potencialidades y futuro, la ciencia como factor desestabilizante y fantástico), Inocencia y delincuencia (la dicotomía planteada lleva al pensamiento estructural que no admite gradaciones o matices, de modo que es luz u oscuridad, verdad o falsedad, bondad o maldad, por lo que es más fácil la instalación de la incertidumbre, del desequilibrio), Fenómeno misterioso de Reviviscencia Arcaica (lo no visto ni aceptado se produce con naturalidad, pero al no serlo concebido ni comprendido es tomado como misterio y con incredulidad), Tragedia del monstruo (empieza a darse cuenta de la nueva realidad: una vida de infortunio, causada por esa pulsión incontrolable, un sentimiento de culpabilidad y acciones de contrición y reparación sin resultados; la conmiseración que causa al lector lo sume en mayor vacilación: ¿es justo que le suceda esto a un hombre? ¿Cuál es la solución? ¿Seremos todos así?), Comentarios sobre la tragedia del monstruo (dos puntos de vista, al del periodista de "Vanguardia" y la del comisario de policía, sin ninguna solución adecuada mostraría una ciudad casi inculta y con escaso nivel científico y llena de temores, lugares comunes, clichés y sin capacidad de reflexión; el origen del asunto se olvidará, tal vez solo se conozca la motivación de los crímenes), A manera de epílogo, ¿Quién era el monstruo? (Razonamiento para mostrar la explicación del fenómeno, pero sin prueba positiva, por lo tanto se impone el final abierto: el misterio continúa y lo fantástico permanece). 
Queda claro, entonces, que la tensión que atraviesa la novela va enhebrándose como una sucesión de escenas (que podrían mostrar un afán cinematográfico del narrador) sintetizadas en los títulos que se construyen como frases utilizadas cotidianamente. Además, la atmósfera literaria del terror, al interior de cada capítulo, se construye con adjetivos visuales muy directos: la mañana radiante, la noche oscura, densa neblina, furioso vendaval, río silencioso, sombras del crepúsculo, silencio sepulcral, paisaje nocturno, carbones encendidos, macizo milenario, tempestad eléctrica, animal gigantesco, aire helado, noches lóbregas y lluviosas, lluvia torrencial, horrendos crímenes, inclinaciones morbosas, desdoblamiento psíquico, guadaña pequeña, suposiciones antojadizas, naturaleza impulsiva, ferocidad arcaica, entre otras. Construida la atmósfera, como lo hemos comprobado, la historia debe tener sostenibilidad. Ello puede darse en un solo inicio, clímax y desenlace, para toda la novela, o en varios a modo de caja china o historias paralelas.

La historia general es sobre el hecho, para el momento (si hemos de aceptar el discurso del profesor Veritas y del periodista de Vanguardia), sobrenatural de la Reviviscencia Arcaica que sufre el protagonista, Juan, que se denomina a sí mismo como El Monstruo, y que lo predispone a la criminalidad. Esa predisposición no es figurativa, sino real: dos muertos por acción de la figura zooórfica, el felino, en el que se convierte y que, de principio, no tiene explicación plausible. Más aún cuando la corporalización sombría de la figura es visible a muchos, lo que lleva a la idea de los pensantes de decir "colapso psicológico de la población". Podría decirse que la novela es la especificación de una idea de connotaciones científicas, un desarrollo de dos teorías muy en boga por la época: el psicoanálisis y la biología (por ello el narrador habla de naturaleza bio-psíquica), por lo tanto una novela de tesis.

Sin embargo, surge una pregunta: ¿por qué construir una novela "vanguardista", que en realidad está emparentada con el romanticismo gótico, negro, oscuro, para mostrar teorías "científicas" modernas? Veamos primero la intencionalidad del autor: "escribirla con la intención de divulgar aún más los conceptos expuestos en dos obras anteriores: "El Hombre y sus Semejanzas Remotas" y "Así Obró el Principio del Placer", y siempre con el deseo de contribuir con un grano de arena más a la Cultura" (p. 3). Para avanzar con seguridad, debemos decir que si Lazarte usa con mayúsculas el término cultura es que tiene en mente la equivalencia semántica, sostenida por Freud, de Civilización y Cultura o Cultura y Civilización: "La palabra "cultura" designa toda la suma de operaciones y normas que distancian nuestra vida de la de nuestros antepasados animales, y que sirven a dos fines: la protección del ser humano frente a la naturaleza y la regulación de los vínculos recíprocos entre los hombres" (Freud 1974: 88).

Al parecer esos fines son los reelaborados por Lazarte y que el narrador, quizá como alter ego, lo cuenta. Sigamos. Pues, al mostrar que el ser humano está siendo atacado por la reviviscencia arcaica, que no puede detener, y que destruye los vínculos recíprocos comunitarios o civilizatorios, especialmente en determinados tipos de personas, como los criminales, sería bueno reconocer los síntomas y los peligros y buscar algún tipo de solución, que para eso es la ciencia. Tal como se observa en el discurso analítico y profundo del profesor Veritas.

Como es usual, las personas en su cotidianidad no "creen" en las bondades de la ciencia a primera vista, solo dan cabida a una nueva estructura mental a partir del asombro o de "una 
experiencia de los límites" (Todorov: 53), por lo que realizarlo usando la literatura, que es "un acto ideológico por derecho propio con la función de inventar "soluciones" imaginarias o formales a contradicciones sociales insolubles" (Jameson: 1989), con características fantásticas, sería una buena estrategia del autor.

¿Fue así? ¿La comunidad huancaína lo aquilató? Al parecer fue todo lo contrario o, tal vez, se asustó más. Apoyando nuestra hipótesis diremos, pues, que ni en 1948 (fecha de la publicación de El Hombre y sus Semejanzas Remotas) ni en 1956 el historiador Tello Devotto (1971) consigna la publicación o presentación de los libros mencionados, como si lo hace en otras ocasiones y de otros autores. No creemos que su publicación haya sido clandestina. Tello, por ejemplo, en su recuento de 1956, informa hasta de "la muerte de uno en Patalá por efectos del rayo" (Patalá es una anexo de Pucará, en las alturas, ¡vaya significación del dato de Tello!). ¿Qué pasó que no hay indicativos de existencia del libro?

Lo que podría suponerse, por las líneas generales del desarrollo histórico de Huancayo, es que fue considerada una "locura" tales ideas (dada la compasión que brinda la iglesia católica) o "heréticas", teniendo en cuenta que Freud, del cual derivan muchas de las ideas de Lazarte, y de su alter ego, siempre consideró a la religión y la religiosidad como una fase "infantil" del ser humano y que necesita "un valimiento aprobatorio de un padre poderoso" o que era, la religión, una "transformación delirante de la realidad efectiva" (Freud: 81). Es decir, el pueblo huancaíno, si bien muy político, como lo muestran las movilizaciones del 14 y 15 de junio de 1956 (tres meses antes de la publicación de la novela: 15 de setiembre de 1956), estaba aún encerrado en la visión de ciudad patricia, señorial y pre burguesa con fuerte contenido de catolicismo, confiaba más en la providencia que en la ciencia.

Y aún más. Verse retratados, como especie humana con tendencias criminales como factores intrínsecos, no debió de ser agradable ni tolerable "en una ciudad culta" (p. 38) como sostiene el narrador que, precisaba el alcalde en la novela, era Huancayo. Imaginamos el terror, después de leer el libro, instalado en casa. El antro imaginario se trasladó a la ciudad y sus viviendas. Ante ello, lo mejor era el "severo silencio", figura adjetival usada por el narrador, de los cultos huancaínos para el libro en cuestión.

Asimismo, las pequeñas historias, tanto las de la selva como en nuestra ciudad ficticia de la novela, sirven de sostén tensional al proceso de creación fantástica del argumento y tema general. La mayoría de ellas viene con incógnitas, con un uso del dato escondido, que serán develadas, unas en el camino, otras en la carta del epílogo, dando fin, supuestamente, al temor o miedo. Pero, como hemos señalado, solo se abre otra tensión (por el final abierto de la novela) ya no contada ni vista.

Si nuestra línea argumental esa adecuada, veamos otro aspecto que está implícito. Lo que se observa es el carácter intrínseco del humano, su biología y su psiquismo. Sin embargo, los hombres y mujeres no son solo eso, sino seres sociales. La implicancia directa sería la idea de Hobbes, mostrada en la novela: "el hombre es el lobo del hombre" (p. 153). Si ello es así, la construcción social es un tejido muy frágil, la sociedad es un sistema muy precario, en el sentido de que la convivencia se verá constantemente agredida y violentada. ¿Qué pasaría si uno de esos "monstruos", uno de esos "individuos dotados de una configuración anatómico terrible, acompañados de instintos sanguinario-sádicos" (p. 97), tomara el poder o el control de la sociedad (fueran autoridades)? La conclusión es lógica y terrible. Pero, a la inversa: 
¿qué pasaría si los "monstruos" solo fueran individuos en la sociedad y el poder lo tuviera uno que ha controlado su "reviviscencia arcaica"?

Es obvio pensar que los lectores inteligentes de este libro serían inoculados por el miedo y el terror ante tal perspectiva. De modo que, al parecer, la contribución "cultural" de Lazarte tuvo demasiadas implicancias y en lugar de hacerla avanzar creó un vacío y lo convirtió en marginal. Ni sus ideas ni su literatura fueron asimiladas a la tradición cultural o social. ¿Ostracismo? Quizá. La sola idea de la sociedad desprotegida o la sola idea de tendencias instintivas nocivas de los individuos, atemorizaban y, tal vez, como los niños, había que esconderse bajo la sábana.

De otro lado, la fantasía puede ser considerada como "realidad revertida" (Montoya: 2004) o como señala Freud: "construcciones defensivas, sublimaciones y embellecimiento de los hechos, sirviendo simultáneamente al propósito de auto exoneración" (Citado por Portocarrero: 76). En consecuencia, ¿qué es lo que revierte, sublima o embellece el narrador, que por cierto no hay que confundir con el autor, en la novela?

En primer lugar, consigue entronizar la idea de que los bajos instintos o la acción de la reviviscencia arcaica es una cualidad nefasta de los hombres, por cierto, por su constante transgresión a las leyes culturales, que deberían reprimirlo en aras de la convivencia social, y a la búsqueda individual, muchas veces en detrimento de lo colectivo, de la realización del programa que impone el principio del placer: el de ser felices. En tanto que las mujeres, especialmente las esposas, al renunciar a lo pulsional, o satisfacción del placer, por lo tanto de la felicidad, crean "la conciencia moral" de la sociedad. En otras palabras, el hombre puede ser perverso, cruel, egoísta, individualista, por lo tanto irresponsable; pero, no la mujer, que es renunciante, bondadosa, estructurante de la familia, por lo tanto de la sociedad (sociedad que, por la acción de los instintivos, se encuentra bajo amenaza de disolución) y llena de amor puro, casi sin sexualidad, por lo tanto con suma responsabilidad.

La descripción de la esposa, para empezar a ver la fantasía literaria, es muy significativa y sugerente: "Amantísima esposa", "Sus facciones, casi perfectas, le daban un aire aristocrático y distinguido. Vestía con decencia pero al mismo tiempo con elegancia. Sus pasos eran cortos y sus movimientos de cuerpo, acompañados de una constante sonrisa en los labios, le hacían irresistible a las miradas de cuanto transeúnte pasaba por su lado". Aquí la palabra "transeúnte" es muy importante para ver el efecto de la sublimación. ¿Las mujeres qué pensarían de otra mujer sonriendo a todos? ¿Se hacía para ellas también "irresistible" mirarla? ¿No sería que la palabra precisa era "cuanto hombre pasaba"? ¿Y ellos, qué pensarían del constante sonreír de una mujer? Es, en realidad, una imagen fantasiosa que buscaría dar firmeza a la historia en tanto afirma la ingenuidad y la pureza de la mujer. Pero, aún hay más para analizar.

La imagen de la integridad moral y al absoluta capacidad de renuncia se observa en el siguiente párrafo: "Y después de conversar (cuando Juan la encuentra en la casa del "amante") largo rato, le propuse que volviera a mi lado, a lo que ella se resistía tenazmente, no porque no quisiera ir conmigo, sino por temor al amante que la había amenazado con matarla si lo abandonaba. Cuando por fin, después de tanto ruego, accedió a mis súplicas y alistaba ya sus ropas en una maleta para seguirme, se presentó el amante y dirigiéndose a ella y con una feroz mirada, preguntó: -¿Quién es este hombre? Ella bañada en llanto, 
respondió: -Es mi esposo. Las facciones del sujeto se encendieron de furor" (p. 169. Las cursivas son nuestras).

Si unimos ambos párrafos veremos que las cualidades son amor pleno, sin mácula, decencia, elegancia, temerosidad (que podría muy bien calar con sacrificada) y de sinceridad en su dolor. ¿Cuánto de esto es verdad? No lo sabemos, solo entendemos que dentro del cuerpo narrativo debemos asumirla como tal, como las heroínas del romanticismo: pletóricas de virtud. Ello, sin embargo, deja preguntas: ¿Las mujeres no pertenecen a la misma especie humana de los hombres, que es la que ha sufrido el proceso evolucionista polifilético y tiene en sí mismo las semejanzas remotas? ¿Si la respuesta es que sí pertenecen a la misma especie, entonces, porqué el narrador la obvia y muestra una fantasía?

En principio, la mujer no es la protagonista de la historia novelesca, por lo tanto, en una primera respuesta, no podía crearse la dicotomía clásica del romanticismo: dos pasiones obstaculizadas. Solo había que mostrarla y luego ocultarla puesto que "la belleza y el encanto son originariamente propiedades del objeto sexual" (Freud: 82), que es lo que desencadena el impulso de la reviviscencia arcaica. Esta razón profunda, en realidad, es lo que lo convierte en fantasía el narrador: hay un "objeto sexual" a disputarse, por ello, la pulsión reprimida rompe las contenciones sociales y finaliza haciendo brotar la forma zoomórfica agresiva. Al negarla en su esencia, y mostrarla como virtuosa, lo que el narrador hace es "una construcción defensiva" que busca la plausibilidad, dado que "denigrar" a una mujer de ese modo esencial solo obtendría rechazo y cuestionamientos severos de una sociedad patriarcal y muy firme en sus criterios de ciudad patricia pre burguesa.

Otra respuesta sería: el mundo que construyen este tipo de mujeres es el de la pureza, la dulzura y la resignación frente al de la violencia, perversidad y crueldad de los hombres. Sería la representación de dos realidades: la civilización construida por la familia, la paz y la estabilidad que debe ser el progreso, ante la barbarie, el caos y la destrucción que trae el progreso de los hombres. Estas dos respuestas no tendrían que ser exclusivas, podrían ser también complementarias.

Otra fantasía, en el mundo novelado de Lazarte, está dada en el orden simbólico, en el Otro, usando la definición de Lacan sobre el tema ("Por el Otro, Lacan se refiere al orden simbólico - las leyes e ideales sociales - que socializa el cuerpo y hace de él un sujeto". Ubilluz 2010: 17), cuando presenta a cuatro componentes: la policía, el poder judicial, los medios de comunicación y la academia. La acción de cada uno de ellos, en principio, debe inscribirse como parte del sistema social, con valoraciones "institucionales" y de responsabilidad. La policía debe cumplir su labor de investigar el delito y dar las pruebas; el poder judicial comprender la causa, interpretarla y dar una sentencia buscando la justicia; los medios de comunicación orientar a la población y dar información fidedigna; y, por último, la academia, la institución educativa, investigar y explicar los fenómenos desde la racionalidad.

Lo que sucede, en la realidad novelesca, es que la policía solo funciona como ente perseguidor y represor (persecución, captura e incomunicabilidad del detenido, que además es otro: "Los guardias que iban tras de mí, me alcanzaron y sin decirme nada, me sujetaron entre todos poniéndome al mismo tiempo las esposas sin atender mis protestas. Luego me condujeron a la Jefatura de Policía, me introdujeron en un calabozo y me tuvieron incomunicado hasta hoy", p. 130). El poder judicial funciona como ente represor y punitivo, 
está más presto a darle credibilidad al fiscal y su retórica antes que a pruebas objetivas, como lo demuestra el abogado del detenido ("Por cuyo motivo que acabo de exponer, de acuerdo con el Art. 152 del Código Penal vigente, pido a este Alto Tribunal que libre a la sociedad del peligro que le amenaza al abrigar en su seno un criminal que ha demostrado poseer caracteres delictuosos jamás observados todavía en ninguna parte del mundo y que, repito, por un capricho de la Naturaleza, se ha presentado entre nosotros causando pavor en los habitantes de la ciudad. Esta es mi opinión señor Presidente", dijo el Fiscal (p. 116, las cursivas son nuestras) "Ahora veamos una de las cosas más importantes que he reservado hasta este instante para probar que mi defendido no es el individuo a quien se acusa de criminal. El abogado puso las fotografías sobre el pupitre... Sí, señor Presidente. He demostrado, pues, que mi defendido no es el criminal sino una víctima propiciatoria de las circunstancias que, por una rara casualidad, encontrábase en el mismo camino por donde el verdadero delincuente, momentos antes, había pasado. Y aquí viene lo grave del caso. El hecho de que el verdadero criminal no esté presente no quiere decir que debe haber alguien quien le sustituya en la prisión", dijo el abogado (p. 122 y 127. Las cursivas son nuestras). Los medios de comunicación funcionan más como sensacionalistas e inquisidores del poder que como indagadores de la verdad como hecho noticioso ("La ciudad se halla en estos instantes atemorizada por la aparición de un ser extraño que ha demostrado ser peligrosísimo para la vida de sus moradores y exige se capture al malhechor lo más pronto posible", dijo el periodista "relámpago" (p. 64. Las cursivas son nuestras). La academia funciona como un cenáculo de hermenéuticos y metafísicos, siempre con hipótesis, con inferencias primarias, nunca con pruebas concluyentes ("Tenemos que ver también las causas de índole biológica donde, como se sabe actúa con carácter dominante, la herencia atávica, quizá con mucha mayor fuerza que las causas atribuidas a la sociedad" "Y más bien creo que se trata de un caso de reviviscencia arcaica" "Así posiblemente habían individuos cuyos rasgos eran semejantes a los felinos..." "Así si Ud., observa un individuo que posee dichos rasgos y, más tarde descubre en otros individuos rasgos semejantes a los de un perro, de un pez de un zorro, de un avestruz, etc., etc., ya puede Ud., deducir, apriorísticamente, que el ser humano no solo puede tener una descendencia simiesca..." "Si pudiera demostrarse efectivamente..." "Llegará quizá un día en que se comprueben..." (pp. 95, 98, 99, 104. Las cursivas son nuestras).

En consecuencia, el punto es: si lo relatado refleja la institucionalidad huancaína de la época, entonces, ellas no encarnaban las "significaciones imaginarias ni la funcionalidad requerida" de la sociedad concreta (" ¿Que son las instituciones? Son redes socialmente sancionadas, formal o informalmente, de reglas y de dispositivos, que encarnan las significaciones imaginarias de la sociedad considerada. Estas instituciones satisfacen siempre también a una funcionalidad" Castoriadis 1996: 11), por lo que no hablaríamos de fantasía, sino de puro realismo crítico expresado literariamente, nada más.

De otro lado, si no es un reflejo institucional-social concreto de Huancayo de la primera mitad del siglo XX, surge la pregunta: ¿por qué el narrador está sublimando, o sea creando una fantasía institucional, a las instituciones? ¿Es una necesidad literaria o es la expresión de una necesidad psíquica?

Castoriadis (1996) señala: "La psiquis no puede sobrevivir más que estando socializada" (p. 13). Freud, de otra parte, señala que las fantasías sirven "al propósito de la auto exoneración" (Citado por Portocarrero: 76). Si usamos estas dos ideas comprenderemos que la 
representación psíquica, expresada en forma literaria, desnuda los psiquismos de los dos sectores, hegemónico y subalterno, huancaínos de la época. Los de arriba: Incompetentes, autoritarios, metafísicos, retóricos, aprovechadores; los de abajo: impulsivos, aterrorizables, temperamentales, ignorantes. Entonces, ¿cuáles son los puntos de encuentro, psíquico y social, para que lo instituido no tenga choques anómicos o destructivos?

El gran marco general social, coincidiendo con José Luis Romero (2011), estaría dado por el agonismo de la ciudad patricia, Huancayo entre 1929 y 1956, y que va a ser una ciudad burguesa fallida en tanto su burguesía señorial se va retirando de la ciudad, generando un vacío en el orden simbólico y económico. El largo tránsito, entre 1956 y 1990, fue un camino de indefiniciones y de creación de lo instituyente en un nuevo contexto social que dejó atrás lo instituido. Es decir, el patriciado huancaíno (burguesía señorial) dejaba de existir para dar paso, no a un burgués huancaíno, sino a un híbrido posmoderno. Pero esto merece otro análisis que no haremos ahora.

Por el lado de la psiquis, la idea de la "auto exoneración" es clave. Se construye esa fantasía para no asumir responsabilidades, pues si lo hubieran hecho habrían tenido que concebir "el imaginario radical: es decir, un imaginario colectivo creador, que está constantemente alimentado por la imaginación radical de los psiquismos singulares" (Castoriadis: 11). Se escondían detrás de que "las instituciones no funcionan", que "tenemos impulsos tenebrosos", "quizá algún día", "estamos aterrorizados y con pánico". Pues, la auto exoneración servía para construir un discurso exculpatorio de sus propias desgracias y subdesarrollo. Es una forma distinta, pero igual, de lo analizado por Portocarrero (1989), hace poco, sobre el tema de "la dominación total" que sufre el peruano en general.

Asumir la responsabilidad de sus propios actos, de otro lado, hubiera creado "la conciencia moral", que, en definitiva, los habría hecho partícipes de la cultura o civilización. Es decir, debían de dejar el principio del placer, renunciar a ello, para construir un nuevo estado de cosas. Desde la perspectiva psicoanalítica esa renuncia aumentaría el sentimiento de culpa, que es "el problema más importante del desarrollo cultural y mostrar que el precio del progreso cultural debe pagarse con el déficit de dicha provocado por la elevación del sentimiento de culpa" (Freud: 130).

En consecuencia, siguiendo el derrotero lógico y sus implicancias de lo que decimos, que pareciera contradictorio, esa auto-exoneración, propuesta por Lazarte y su alter ego, resulta una fantasía creadora, en el sentido de crítico con connotaciones dialécticas. Es decir, esa fantasía, en realidad, debía crear una motivación para crear "el imaginario radical" puesto que desnudaba todos los vicios sociales y las debilidades que impedían el verdadero progreso y desarrollo histórico-social. Si el desarrollo o progreso debía tener un precio, tanto individual como social, no era ajeno al ser humano, pues así lo había sido siempre. El discurso del profesor Veritas, aun con sus deducciones apriorísticas, lo demuestra. Pues, justamente la ciencia servía para eso. Él mismo, Veritas, era ejemplo de renuncias con sublimaciones de "desempeñar un papel sustantivo en la vida cultural". No solo es importante, se siente importante, lo que aminora su desdicha, pues siente el "aparecer más fino y superior" (Freud: 79).

Esta fantasía creadora, por lo tanto, debía de señalar un nuevo rumbo a toda la comunidad huancaína. Debía, pero no fue. El hecho histórico de la desestructuración del sistema semifeudal, donde tenía asiento la ciudad patricia, vino a conspirar definitivamente contra 
un progreso de estilo burgués. ¿Tendrá, la ciudad, otra oportunidad en nuevas condiciones? No lo sabemos.

\section{BIBLIOGRAFÍA}

CASTORIADIS, Cornelio (1996): Psique e historia. Argentina, Omegaalfa.es

FREUD, Sigmund. (1974/1992): "El malestar en la cultura", Obras completas T. XXI. Buenos Aires, Amorrortu editores.

LAZARTE, Alfonso (1948): El hombre y sus semejanzas remotas. Huancayo. Editora Huancayo.

LAZARTE, Alfonso. (1956). El antro de la brujas. Huancayo. Editorial La inmaculada.

MONTOYA, Víctor (2004): "El poder de la fantasía", en Letralia. Año IX. N 112. Cagua. Venezuela. http://www.letralia.com/112/ensayo01.htm, Fecha de extracción: 15-082014

PORTOCARRERO, Gonzalo (1984): “La dominación total”, en Debates en sociología, 10. Lima.

PORTOCARRERO, Gonzalo (1989): Castigo sin culpa, culpa sin castigo. Lima.

PORTOCARRERO, Gonzalo (2004): Los rostros criollos del mal. Cultura y transgresión en la sociedad peruana. Lima, RPDCCSSP.

ROMERO, José (2011): Latinoamérica, las ciudades y las ideas, 3ra edición, Buenos Aires. Siglo XXI.

TELLO, Ricardo (1971): Historia de la Provincia de Huancayo. Huancayo, Editorial San Fernando.

TODOROV, Tzvetan (1981): Introducción a la literatura fantástica. México, Premia editora.

UBILlUZ, Juan Carlos (2010): Nuevos súbditos. Cinismo y perversión en la sociedad contemporánea. Lima, EIP.

(C) Alberto Chavarría Muñoz

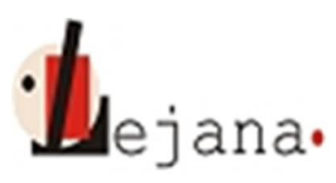

http://lejana.elte.hu

Universidad Eötvös Loránd, Departamento de Español, 1088 Budapest, Múzeum krt. 4/C

Recibido: 26 de junio de 2015

Aceptado: 13 de septiembre de 2015 